\title{
Endophthalmitis after open globe injuries: changes in microbiological spectrum and isolate susceptibility patterns over 14 years
}

Animesh Jindal', Avinash Pathengay ${ }^{1 *}$, Kopal Mithal ${ }^{1}$, Subhadra Jalali², Annie Mathai ${ }^{2}$, Rajeev Reddy Pappuru², Raja Narayanan ${ }^{2}$, Jay Chhablani ${ }^{2}$, Swapna R Motukupally ${ }^{4}$, Savitri Sharma ${ }^{4}$, Taraprasad Das ${ }^{2,3}$ and Harry W Flynn $\mathrm{Jr}^{5}$

\begin{abstract}
Background: The objective of this study was to evaluate the microbiologic spectrum and antimicrobial susceptibility of isolates in post-traumatic endophthalmitis and compare with our earlier published report. A retrospective review was conducted on 581 consecutive patients with culture-proven post-traumatic endophthalmitis at L. V. Prasad Eye Institute, India, from January 2006 to March 2013.

Findings: A total of 620 isolates from 581 patients were identified ( 565 bacteria and 55 fungi). The most common isolate was Bacillus spp. (106/620, 17.1\%) closely followed by Streptococcus pneumoniae (105/620, 16.9\%), and coagulase-negative Staphylococci (97/620, 15.6\%). In our earlier report, the commonest bacteria included Streptococcus spp. (30/139, 21.6\%) and gram-positive coagulase-negative micrococci (26/139, 18.7\%). Gram-positive isolates were usually susceptible to vancomycin (98.2\%). Gram-negative isolates were generally susceptible to gatifloxacin (92.9\%), ofloxacin (89.4\%), chloramphenicol (88.6\%, Pseudomonas isolates were often resistant), amikacin (83.5\%), and ceftazidime (77.2\%). Fourteen years ago, the most sensitive antibiotic was ciprofloxacin for both gram-positive bacteria (95.12\%) and gram-negative bacteria (100\%).

Conclusions: The microbiological spectrum of post-traumatic endophthalmitis has remained unchanged over the last 14 years, and Bacillus spp. continues as the most common infecting organism. Vancomycin is the drug of choice for empiric coverage of gram-positive bacteria. Susceptibility of gram-negative bacteria to commonly used antimicrobials (amikacin and ciprofloxacin) has decreased by $10 \%-15 \%$ and to ceftazidime has increased by $10.5 \%$.
\end{abstract}

Keywords: Open globe injury; Endophthalmitis; Microbiology

\section{Findings}

\section{Background}

Open globe injuries (OGI) are a common cause of infectious endophthalmitis. The incidence of endophthalmitis in this setting varies from $3 \%$ to $48 \%$ in various studies, depending on a variety of factors which include setting of trauma, delay of repair, retained intraocular foreign body, and involvement of the crystalline lens [1]. Posttraumatic endophthalmitis is either a community-acquired infection from the unsterile material causing trauma or caused by the inoculation of the normal ocular flora at the

\footnotetext{
* Correspondence: avinash@lvpei.org

${ }^{1} \mathrm{~L}$ V Prasad Eye Institute, GMR Varalakshmi Campus, Visakhapatnam 530040, India

Full list of author information is available at the end of the article
}

time of injury. The purpose of the study is to describe the microbial spectrum and antimicrobial susceptibility in cases of endophthalmitis after OGI and to compare the results with the earlier published data from the same center [2].

\section{Methods}

This was a retrospective, non-comparative, consecutive case series. Microbiology records were reviewed of all the culture-proven endophthalmitis cases after OGI treated at L. V. Prasad Eye Institute, Hyderabad, India, between January 2006 and March 2013. Bacterial isolates were identified using Analytical Profile Index (API, Bio Meriux, France). The isolate susceptibility to various antimicrobials was determined by the Kirby-Bauer disk diffusion method. 
Table 1 Microbiological spectrum and antimicrobial susceptibilities in patients with endophthalmitis following open globe injuries

\begin{tabular}{|c|c|c|c|c|c|c|c|c|c|c|c|c|c|c|c|c|c|c|c|c|c|c|c|c|c|c|c|c|c|c|c|c|}
\hline \multirow[t]{2}{*}{ Organism } & \multirow{2}{*}{$\begin{array}{l}\text { Total/ } \\
\text { percentage } \\
\text { (previous } \\
\text { study) }\end{array}$} & \multirow{2}{*}{$\begin{array}{l}\text { Total/ } \\
\text { percentage } \\
\text { (current } \\
\text { study) }\end{array}$} & \multicolumn{3}{|c|}{ Amikacin } & \multicolumn{3}{|c|}{ Cefazolin } & \multicolumn{3}{|c|}{ Ceftazidime } & \multicolumn{3}{|c|}{ Chloramphenicol } & \multicolumn{3}{|c|}{ Gentamicin } & \multicolumn{3}{|c|}{ Gatifloxacin } & \multicolumn{3}{|c|}{ Ciprofloxacin } & \multicolumn{3}{|c|}{ Moxifloxacin } & \multicolumn{3}{|c|}{ Vancomycin } & \multicolumn{3}{|c|}{ Ofloxacin } \\
\hline & & & $n$ & $s$ & $\%$ & $n$ & $s$ & $\%$ & $n$ & $s$ & $\%$ & $n$ & $s$ & $\%$ & $n$ & $s$ & $\%$ & $n$ & $s$ & $\%$ & $n$ & $s$ & $\%$ & $n$ & $s$ & $\%$ & $n$ & $s$ & $\%$ & $n$ & $s$ & $\%$ \\
\hline Gram-positive cocci & $63 / 45.3$ & $296 / 47.7$ & 274 & 155 & 56.5 & 294 & 266 & 90.4 & 137 & 79 & 57.6 & 295 & 284 & 96.2 & 295 & 217 & 73.5 & 292 & 263 & 90.1 & 296 & 219 & 73.9 & 239 & 206 & 86.2 & 289 & 284 & 98.2 & 295 & 240 & 81.4 \\
\hline $\begin{array}{l}\text { Coagulase- } \\
\text { negative } \\
\text { Staphylococcus }\end{array}$ & $25 / 18$ & $97 / 15.6$ & 86 & 81 & 94.2 & 96 & 90 & 93.7 & 41 & 18 & 43.9 & 96 & 93 & 96.9 & 97 & 89 & 91.7 & 97 & 96 & 98.9 & 97 & 75 & 77.3 & 75 & 69 & 92 & 95 & 93 & 97.9 & 97 & 76 & 78.4 \\
\hline $\begin{array}{l}\text { Staphylococcus } \\
\text { aureus }\end{array}$ & $5 / 3.6$ & $11 / 1.8$ & 11 & 11 & 100 & 11 & 11 & 100 & 5 & 3 & 60 & 11 & 11 & 100 & 11 & 10 & 90.9 & 11 & 10 & 90.9 & 11 & 5 & 45.4 & 10 & 8 & 80 & 11 & 11 & 100 & 11 & 6 & 54.5 \\
\hline Streptococcus sp. & $30 / 21.6$ & $172 / 27.7$ & 163 & 52 & 31.9 & 172 & 154 & 89.5 & 81 & 54 & 66.6 & 172 & 166 & 96.5 & 172 & 108 & 62.7 & 169 & 143 & 84.6 & 172 & 127 & 73.8 & 143 & 119 & 83.2 & 168 & 165 & 98.2 & 171 & 143 & 83.6 \\
\hline $\begin{array}{l}\text { Other gram- } \\
\text { positive cocci }\end{array}$ & $3 / 2.2$ & $16 / 2.6$ & 14 & 11 & 78.6 & 15 & 11 & 73.3 & 10 & 4 & 40.0 & 16 & 14 & 87.5 & 15 & 10 & 66.7 & 15 & 14 & 93.3 & 16 & 12 & 75.0 & 11 & 10 & 90.9 & 15 & 15 & 100 & 16 & 15 & 93.7 \\
\hline Gram-positive bacilli & $24 / 17.3$ & $117 / 18.8$ & 114 & 109 & 95.6 & 115 & 63 & 54.7 & 75 & 12 & 16 & 117 & 109 & 93.1 & 117 & 112 & 95.7 & 117 & 116 & 99.1 & 116 & 108 & 93.1 & 101 & 99 & 98.0 & 114 & 109 & 95.6 & 117 & 116 & 99.1 \\
\hline Bacillus sp. & $20 / 14.4$ & $106 / 17.1$ & 103 & 101 & 98.1 & 104 & 54 & 51.9 & 67 & 8 & 11.9 & 106 & 98 & 92.4 & 106 & 105 & 99.1 & 106 & 105 & 99.0 & 106 & 101 & 95.2 & 94 & 92 & 97.9 & 103 & 98 & 95.1 & 106 & 106 & 100 \\
\hline Other GPB & $4 / 2.9$ & $11 / 1.8$ & 11 & 8 & 72.7 & 11 & 9 & 81.8 & 8 & 4 & 50 & 11 & 11 & 100 & 11 & 7 & 63.6 & 11 & 11 & 100 & 10 & 7 & 70 & 7 & 7 & 100 & 11 & 11 & 100 & 11 & 10 & 90.9 \\
\hline $\begin{array}{l}\text { Gram negative } \\
\text { organism }\end{array}$ & $25 / 18$ & $142 / 25$ & 140 & 117 & 83.5 & 16 & 7 & 43.7 & 136 & 105 & 77.2 & 141 & 125 & 88.6 & 142 & 125 & 88.0 & 141 & 131 & 92.9 & 142 & 123 & 86.6 & 116 & 96 & 82.7 & 16 & 4 & 25 & 142 & 127 & 89.4 \\
\hline Pseudomonas sp. & $10 / 7.2$ & $16 / 2.6$ & 16 & 12 & 75 & 1 & 0 & 0 & 16 & 11 & 68.7 & 16 & 5 & 31.2 & 16 & 12 & 75 & 16 & 12 & 75.0 & 16 & 11 & 68.7 & 13 & 8 & 61.5 & 1 & 0 & 0 & 16 & 11 & 68.7 \\
\hline Enterobacter sp. & $2 / 1.4$ & $25 / 4.0$ & 25 & 22 & 88 & 5 & 2 & 40 & 23 & 21 & 91.3 & 25 & 24 & 96 & 24 & 23 & 95.8 & 25 & 24 & 96 & 25 & 24 & 96 & 19 & 19 & 100 & 5 & 2 & 40 & 25 & 24 & 96 \\
\hline E. coli & $4 / 2.9$ & $14 / 2.3$ & 14 & 12 & 85.7 & - & - & - & 14 & 12 & 85.7 & 14 & 13 & 92.8 & 14 & 13 & 92.8 & 14 & 11 & 78.6 & 14 & 11 & 78.6 & 12 & 7 & 58.3 & - & - & - & 14 & 10 & 71.4 \\
\hline Haemophilus sp. & - & $14 / 2.3$ & 14 & 7 & 50 & - & - & - & 13 & 5 & 38.5 & 14 & 14 & 100 & 14 & 11 & 78.6 & 14 & 14 & 100 & 14 & 12 & 85.7 & 13 & 11 & 84.6 & - & - & - & 14 & 14 & 100 \\
\hline $\begin{array}{l}\text { Other gram- } \\
\text { negative organisms }\end{array}$ & $9 / 6.5$ & $73 / 11.8$ & 71 & 64 & 90.1 & 10 & 5 & 50 & 70 & 56 & 80 & 72 & 69 & 95.8 & 74 & 66 & 89.2 & 72 & 70 & 97.2 & 73 & 65 & 89 & 59 & 51 & 86.4 & 10 & 2 & 20 & 73 & 68 & 93.2 \\
\hline Corynebacterium & $5 / 3.6$ & $10 / 1.6$ & 5 & 4 & 80 & 10 & 9 & 90 & 3 & 0 & 0 & 10 & 9 & 90 & 10 & 9 & 90 & 10 & 9 & 90.0 & 10 & 7 & 70 & 8 & 6 & 75.0 & 10 & 10 & 100 & 10 & 9 & 90 \\
\hline Total bacteria & $119 / 85.6$ & $565 / 91.1$ & 533 & 385 & 72.2 & 435 & 345 & 79.3 & 351 & 196 & 55.8 & 563 & 527 & 93.6 & 564 & 463 & 82.0 & 560 & 519 & 92.7 & 564 & 457 & 81.1 & 464 & 407 & 87.7 & 429 & 407 & 94.8 & 564 & 492 & 87.2 \\
\hline Total fungi & 20/14.4 & $55 / 8.9$ & & & & & & & & & & & & & & & & & & & & & & & & & & & & & & \\
\hline Aspergillus & $9 / 6.5$ & $20 / 3.2$ & & & & & & & & & & & & & & & & & & & & & & & & & & & & & & \\
\hline Acremonium & $1 / 0.7$ & $1 / 0.32$ & & & & & & & & & & & & & & & & & & & & & & & & & & & & & & \\
\hline Bipolaris & $1 / 0.7$ & $2 / 0.32$ & & & & & & & & & & & & & & & Not do & & & & & & & & & & & & & & & \\
\hline Cladosporium & $1 / 0.7$ & $2 / 0.32$ & & & & & & & & & & & & & & & & & & & & & & & & & & & & & & \\
\hline Candida & - & $3 / 0.48$ & & & & & & & & & & & & & & & & & & & & & & & & & & & & & & \\
\hline Fusarium & $2 / 1.4$ & $1 / 0.16$ & & & & & & & & & & & & & & & & & & & & & & & & & & & & & & \\
\hline
\end{tabular}

All isolates were not tested for susceptibility to all antibiotics leading to ' $n$ ' being less than the total isolates. GPB, gram-positive bacilli; $n$, number of isolates tested for antibiotic susceptibility; $S$, number of isolates sensitive to the antibiotic. 
Susceptibilities for fungal isolates were not performed. The study was approved by the Institutional Review Board of L. V. Prasad Eye Institute and adhered to the guidelines of the Declaration of Helsinki.

\section{Results}

A total of 620 isolates from 581 samples were identified. A total of 38 samples (6.5\%) had polymicrobial infection; 37 samples grew two isolates, and one sample grew three organisms. The isolates included gram-positive cocci (296, 47.7\%), gram-positive bacilli (117, 18.8\%), gram-negative bacteria (142, 22.9\%), fungi $(55,8.87 \%)$, and Corynebacterium (10, 1.61\%) (Table 1).

The most common organism isolated was Bacillus spp. (106/620, 17.1\%) followed by Streptococcus pneumoniae $(105 / 620,16.9 \%)$ and coagulase-negative Staphylococci (97/620, 15.6\%). Enterobacter was the most common gramnegative isolate (25 of 142 gram-negative isolates). Aspergillus spp. was the most common fungus (20 of 55 fungal isolates) (Table 1).

The spectrum of the isolates identified in this series was similar to that reported in 1999 from the same center [2], with coagulase-negative Staphylococci (CoNS), Streptococcus, and Bacilllus sp. being the three most common organisms (Table 1). The only differences in the spectrum of organisms were the relatively lower incidence of fungal endophthalmitis in the current study (current $8.9 \%$ vs earlier 14.4\%) and higher incidence of gram-negative isolates (current 25\% vs earlier 18\%). But, both of these were not statistically significant ( $p=0.257$ and 0.058 , respectively).

Both gram-positive cocci and gram-positive bacilli were generally susceptible to vancomycin $(98.2 \%$ and $95.6 \%$, respectively). Bacillus sp. was also susceptible to vancomycin (95.1\%) as well as to gentamicin (99.1\%), amikacin (98.1\%), chloramphenicol (92.4\%), ciprofloxacin (95.2\%), ofloxacin (100\%), gatifloxacin (99.1\%), and moxifloxacin (97.9\%) but its susceptibility to ceftazidime was very poor (11.9\%). Gram-negative bacteria were generally susceptible to gatifloxacin (92.9\%) followed by ofloxacin $(89.4 \%)$, chloramphenicol (88.6\%), ciprofloxacin (86.6\%), amikacin (83.5\%), and ceftazidime (77.2\%). Among the fluoroquinolones, both gram-positive and gram-negative organisms were most susceptible to gatifloxacin $(92.7 \%$ and $92.9 \%$, respectively). The antimicrobial susceptibilities of the various isolates are detailed in the Table 1.

\section{Discussion}

The susceptibility of gram-positive organisms continues to be highest to vancomycin. Susceptibility of CoNS to ciprofloxacin had reduced from $100 \%$ in 1999 report [2] to $77.3 \%$ in the current report $(p=0.007)$. Similar fluoroquinolone susceptibility trend towards CoNS was noted in the report by Schimel et al. [3]. Susceptibility of gramnegative organisms has slightly decreased over the last two decades. In the 1999 report, gram-negative organisms were $100 \%$ susceptible to ciprofloxacin and $95 \%$ to amikacin [2]. This has now reduced to $86.6 \%$ and $83.5 \%$, respectively, but this change was statistically not significant ( $p=0.078$ and $p=0.206$, respectively). The susceptibility of gram-negative isolates to ceftazidime has increased from $66.7 \%$ in 1999 [2] to $77.2 \%$ in the current study, and this difference is also not significant $(p>0.05)$.

The current study indicates that the microbiological spectrum in post-traumatic endophthalmitis has remained the same over the last two decades. Intravitreal vancomycin remains the drug of choice for empiric coverage of gram-positive bacteria. Susceptibility of gram-negative bacteria to commonly used antimicrobials including amikacin and ciprofloxacin has decreased by $10 \%$ to $15 \%$ and to ceftazidime has increased by $10.5 \%$ as compared to the past two decades though statistically not significant. Thus, intravitreal amikacin can be used for empiric coverage of gram-negative bacteria. Ofloxacin is a good option as a systemic antibiotic for broad-spectrum empiric coverage. Also, we report a high prevalence of Bacillus endophthalmitis in open globe injuries that are known to be highly virulent with rapid progression to panophthalmitis [4]. Similar high prevalence of Bacillus endophthalmitis following open globe injuries has been reported in the literature $[5,6]$.

\section{Conclusions}

The microbiological spectrum remains similar over the past 14 years. The susceptibility of gram-negative organisms to commonly used antibiotics has decreased over the time period. Empiric treatment of post-traumatic endophthalmitis with broad-spectrum, combination antibiotics based on the susceptibility pattern in that region is very important for successful anatomical and visual outcomes.

\section{Competing interests}

The authors declare that they have no competing interests.

\section{Authors' contributions}

AJ carried out the data collection and data analysis and drafted the manuscript. AP is one of the treating physicians and also carried out the correction of the manuscript. KM, SJ, AM, RRP, RN, JC, and TD are the other treating physicians. SRM and SS are the microbiologists. TD and HWFJ corrected the manuscript. All authors read and approved the final manuscript.

\section{Author details}

${ }^{1}$ L V Prasad Eye Institute, GMR Varalakshmi Campus, Visakhapatnam 530040, India. ${ }^{2}$ Srimati Kannuri Santhamma Centre for Vitreoretinal Diseases, L V Prasad Eye Institute, KAR Campus, Hyderabad 500034, India. ${ }^{3} \mathrm{~L}$ V Prasad Eye Institute, Bhubaneswar Eye Institute, Bhubaneswar, Odisha 751024, India. ${ }^{4}$ Jhaveri Microbiology Centre, L V Prasad Eye Institute, KAR Campus, Hyderabad 500034, India. ${ }^{5}$ Department of Ophthalmology, Bascom Palmer Eye Institute, Miller School of Medicine, University of Miami, Miami, FL 33124, USA.

Received: 29 December 2013 Accepted: 10 February 2014 Published: 18 February 2014 


\section{References}

1. Zhang $Y$, Zhang MN, Jiang $\mathrm{CH}$, Yao Y, Zhang $\mathrm{K}$ (2010) Endophthalmitis following open globe injury. Br J Ophthalmol 94:111-114

2. Kunimoto DY, Das T, Sharma S, Jalali S, Majji AB, Gopinathan U, Athmanathan S, Rao TN (1999) Microbiologic spectrum and susceptibility of isolates: part II. Posttraumatic endophthalmitis. Endophthalmitis Research Group. Am J Ophthalmol 128:242-244

3. Schimel AM, Miller D, Flynn HW Jr (2013) Endophthalmitis isolates and antibiotic susceptibilities: a 10-year review of culture-proven cases. Am J Ophthalmol 156:50-52

4. Ahmed Y, Schimel AM, Pathengay A, Colyer MH, Flynn HW Jr (2012) Endophthalmitis following open-globe injuries. Eye (Lond) 26:212-217

5. Bhagat N, Nagori S, Zarbin M (2011) Post-traumatic infectious endophthalmitis. Surv Ophthalmol 56:214-251

6. Thompson JT, Parver LM, Enger CL, Mieler WF, Liggett PE (1993) Infectious endophthalmitis after penetrating injuries with retained intraocular foreign bodies. National Eye Trauma System. Ophthalmology 100:1468-1474

doi:10.1186/1869-5760-4-5

Cite this article as: Jindal et al:: Endophthalmitis after open globe injuries: changes in microbiological spectrum and isolate susceptibility patterns over 14 years. Journal of Ophthalmic Inflammation and Infection 2014 4:5.

\section{Submit your manuscript to a SpringerOpen ${ }^{\circ}$ journal and benefit from:}

- Convenient online submission

- Rigorous peer review

- Immediate publication on acceptance

- Open access: articles freely available online

- High visibility within the field

- Retaining the copyright to your article 